\title{
Movimentos sociais e educação ambiental: um estudo sobre teses e dissertações brasileiras
}

\section{Social movements and environmental education research: a study on Brazilian theses and dissertations}

\author{
Larissa Nobre Magacho1 ${ }^{1}$. https://orcid.org/0000-0002-5052-1280 \\ Rosa Maria Feiteiro Cavalari ${ }^{1}$. https://orcid.org/0000-0002-3782-2396
}

\begin{abstract}
Resumo: O presente trabalho tem por objetivo investigar que relações entre movimentos sociais e Educação Ambiental (EA) têm sido estabelecidas nas teses e dissertações (TD) brasileiras da área. O trabalho se caracteriza como uma pesquisa documental do tipo estado da arte. A constituição do corpus documental compreendeu as seguintes etapas: definição dos termos de busca, leitura flutuante dos resumos, definição de critérios para seleção, busca e leitura dos trabalhos completos e, por fim, definição do corpus documental definitivo, resultando em nove TD para análise. Identificamos pesquisas que estudaram o movimento ambientalista, os movimentos sociais campesinos e, com menor expressividade, o movimento feminista. Foram recorrentes as contribuições da EA para os movimentos sociais analisados e, também, dos movimentos sociais para a construção da EA em sua perspectiva crítica. Esperamos que, com esses conhecimentos construídos, seja possível o estreitamento das relações entre o campo de pesquisa da EA e dos movimentos sociais.
\end{abstract}

Palavras-chave: Educação ambiental. Movimentos sociais e educação. Pesquisa bibliográfica. Estado da arte. Banco de teses.

\begin{abstract}
This paper seeks to investigate the relationship between social movements and Environmental Education (EE) in Brazilian theses and dissertations (TD) in EE. It is a state-of-the-art type of research. The development of the documentary corpus included the following steps: definition of search terms; floating reading of abstracts; definition of criteria for selection; search for and reading of the complete works and, finally, definition of the definitive documentary corpus, resulting in nine TDs for analysis. Studies have been identified that deal with the environmental movement, rural social movements and less markedly - the feminist movement. The contributions of EE to the analyzed social movements and to social movements for the construction of EE in their critical perspective were recurrent. We hope that the construction of this knowledge will make it possible to strengthen relations between the research field of EA and social movements.
\end{abstract}

Keywords: Environmental education. Social movements and education. Bibliographic research. Stateof-art. Theses database.

\footnotetext{
${ }^{1}$ Universidade Estadual Paulista (UNESP), Instituto de Biociências, Rio Claro, SP, Brasil. Email: r.cavalari@unesp.br
} 


\title{
Introdução
}

Desde os primórdios da sua história na Terra, o ser humano se relacionou com a natureza. Essa relação é fundamental para a garantia da sua sobrevivência e existe mediante a realização do trabalho, no qual ambos os envolvidos - ser humano e natureza - são modificados em um processo dialético, de acordo com o referencial teórico marxista. Assim, a exploração da natureza pelos seres humanos é intrínseca à existência da espécie no planeta. No entanto, no decorrer da história, o ser humano passou a explorar a natureza de forma exacerbada, desrespeitando seus limites e a sua capacidade de resiliência. Esse modo de relacionar-se com a natureza, por sua vez, gerou uma série de consequências negativas para a humanidade e para os outros seres vivos.

Crise ambiental é um termo que vem sendo adotado por alguns autores, por exemplo, LEFF (2001), bem como pela mídia, para referir-se a esses cenários. Nesta pesquisa, optamos pela utilização do termo crise socioambiental ou crise do capital (FOLADORI, 2001), tendo em vista sua complexidade e sua relação com as desigualdades sociais produzidas pelo modo de produção capitalista. Segundo o mesmo autor, a necessidade de acúmulo do capital, somada à crise estrutural intrínseca a esse modelo, induzem a uma série de ações destrutivas, que afetam o trabalho, a natureza e a sobrevivência da humanidade.

Foladori (2001) explana que essas ações se manifestam na exploração descontrolada dos recursos naturais, gerando riscos ambientais e sociais, como poluição de rios e mares, desmatamento, perda de biodiversidade, insegurança alimentar, entre outros. Cabe destacar que os riscos gerados não atingem todas as pessoas da mesma forma, sendo que, as comunidades em condições de vulnerabilidade são as mais atingidas pelas consequências das alterações ambientais.

Nessa perspectiva, a noção de justiça ambiental, de acordo com Acselrad (2010, p. 110),

\begin{abstract}
[...] identifica a desigual exposição ao risco como resultado de uma lógica que faz que a acumulação de riqueza se realize tendo por base a penalização ambiental dos mais despossuídos. A operação dessa lógica estaria associada ao funcionamento do mercado de terras, cuja “ação de coordenação” faz que práticas danosas se situem em áreas desvalorizadas, assim como à ausência de políticas que limitem a ação desse mercado.
\end{abstract}

Evidenciadas as desigualdades distributivas dos riscos ambientais, abre-se espaço para a percepção e denúncia de que o ambiente de certos grupos sociais é privilegiado em detrimento de outros, dando visibilidade àquilo que se convencionou denominar como conflito ambiental (ACSERALD, 2010). Os conflitos causados por situações de ausência de justiça ambiental podem produzir o efeito contrário: a resistência. A partir da resistência às situações de riscos socioambientais, emergem certos movimentos sociais e suas lutas por justiça ambiental, em todas as regiões em que esse modelo acelerado de industrialização é imposto.

Considerando que poucos foram os autores que buscaram formular e delimitar o conceito de movimentos sociais na sociologia, esta pesquisa adota como referência a conceituação de Gohn (2006), que afirma que os movimentos sociais são 
[...] ações sociopolíticas construídas por atores sociais coletivos pertencentes a diferentes classes e camadas sociais, articuladas em certos cenários da conjuntura socioeconômica e política de um país, criando um campo político de força social na sociedade civil [...] As ações desenvolvem um processo social e político-cultural que cria uma identidade coletiva para o movimento, a partir dos interesses em comum. Esta identidade é amalgamada pela força do princípio da solidariedade e construída a partir da base referencial de valores culturais e políticos compartilhados pelo grupo, em espaços coletivos não-institucionalizados. Os movimentos participam portanto da mudança social histórica de um país e o caráter das transformações geradas poderá ser tanto progressista quanto conservador ou reacionário, dependendo das forças sociopolíticas a que estão articulados, em suas densas redes; e dos projetos políticos que constroem com suas ações. Eles têm como base de suporte entidades e organizações da sociedade civil e política, com agendas de atuação construídas ao redor de demandas socioeconômicas ou políticoculturais que abrangem as problemáticas conflituosas da sociedade onde atuam (GOHN, 2006, p. 251).

De acordo com Acserald (2010), alguns movimentos sociais inserem a temática ambiental, articulada à noção de justiça ambiental, nas suas lutas e proposições ao longo do tempo, com o objetivo de reinventar as relações sociais dos seres humanos entre si e destes com a natureza. Para o autor, contextualizado nesses movimentos encontra-se o próprio movimento ambientalista e, também, aqueles que não se autodenominam ambientalistas. Enquadram-se nessa categoria alguns movimentos indígenas, o Movimento dos Seringueiros, liderado pelo sindicalista Chico Mendes, o Movimento dos Trabalhadores Rurais Sem Terra (MST), o Movimento dos Atingidos por Barragens (MAB).

De forma menos expressiva, existem, ainda, correntes do ecofeminismo que articulam a temática ambiental às lutas do movimento feminista, incorporando, em algumas vertentes, a noção de justiça ambiental (RODRÍGUEZ; LÓPEZ, 2010).

A partir da década de 1960, o processo educativo passou a ser evidenciado enquanto possibilidade de mitigação, e até mesmo de superação, da crise socioambiental, configurando certo otimismo pedagógico em relação ao papel da educação nesse processo (CARVALHO, 1989). Nesse sentido, concordamos com o autor, quando pontua a necessidade de levarmos em conta os limites e possibilidades da educação, uma vez que, "muitas vezes, a contribuição do processo educativo para as mudanças almejadas é de tal forma supervalorizada que leva facilmente à idealização ou à mistificação" (CARVALHO, 2006, p. 3). Dessa forma, entendemos que a educação deva ser compreendida como parte integrante e indissociável do conjunto de outras ações rumo à transformação social, e não como único caminho para alcançar esse objetivo.

A necessidade de construir caminhos para a integração entre a temática ambiental e o processo impulsionou, e continua impulsionando, um amplo debate, que ocorre nos mais variados contextos, como grupos de pesquisas e eventos tais como congressos, conferências e seminários da agenda internacional. A partir dessas interlocuções, emergiu a noção de Educação Ambiental (EA) (CARVALHO, 1989). 
Após um longo período de institucionalização e consolidação do campo de pesquisa da EA, os educadores ambientais perceberam que, assim como existem diferentes concepções de natureza, meio ambiente, sociedade e educação, também existem diferentes concepções de EA, o que, por sua vez, resulta em diferentes práticas educacionais (LAYRARGUES; LIMA, 2014). Com o objetivo de mapear as macrotendências pedagógicas da EA, esses autores realizaram um estudo e identificaram três grandes macrotendências: a conservacionista, a pragmática e a crítica.

Nesta pesquisa, adotamos como referência a macrotendência crítica da EA, tendo em vista que essa inclui, no debate ambiental, a compreensão dos mecanismos da reprodução social, bem como a compreensão de que as relações entre o ser humano e a natureza são mediadas por relações socioculturais e de classe, historicamente construídas. Compreendemos, então, que a chamada macrotendência crítica enfoca os problemas ambientais associados aos problemas sociais, uma vez que são reflexos das relações sociais, dos modelos de sociedade e de desenvolvimento. Assim sendo, a macrotendência crítica da EA objetiva o enfrentamento político das desigualdades socioambientais, estando, ela mesma, permeada pelas noções de conflito e justiça ambiental.

De acordo com a EA crítica, que integra as noções de risco, conflito e justiça ambiental, os movimentos sociais ocupam posição de destaque, tendo em vista o seu protagonismo nas discussões sobre o processo educativo ambiental (LOUREIRO, 2008). Além disso, pensar os movimentos sociais no âmbito da EA representa ganhos qualitativos no que concerne ao atendimento dos objetivos e diretrizes da Educação Ambiental.

Além dos citados ganhos qualitativos, trazem para a problemática ambiental:

[...] os conflitos socioambientais, os problemas decorrentes dos usos e apropriações da natureza, os interesses e necessidades em disputa, as visões societárias antagônicas, a configuração política e institucional, as mobilizações sociais; enfim, os agentes sociais concretos em suas relações constitutivas na dinâmica contraditória da sociedade (ACSELRAD, 2004; ACSELRAD; HERCULANO; PÁDUA, 2004; QUINTAS, 2000 apud LOUREIRO, 2008, p. 191).

No campo de pesquisa em EA, a pesquisa sobre os movimentos sociais ainda pode ser considerada recente e vem ganhando destaque, principalmente após a criação do Grupo de Pesquisa (GDP) do Encontro de Pesquisa em Educação Ambiental (EPEA) denominado "Pesquisa em EA e Movimentos sociais", hoje conhecido por Pesquisa em EA, movimentos sociais e justiça ambiental.

Mesmo encontrando algumas pesquisas que abordam, explicitamente, a relação entre EA e movimentos sociais, cabe ressaltar que os estudos sobre essa temática ainda são incipientes (KAWASAKI et al., 2009; LOUREIRO, 2008). Tendo em vista a relevância e a lacuna na produção científica dessa temática no campo da EA, Vasconcellos et al. (2009, p. 41) alertam para a necessidade de inserção de uma "chamada aos pesquisadores e pesquisadoras brasileiros", com o intuito de amadurecer a interface e realizar conexões adequadas entre Educação Ambiental e movimentos sociais.

Considerando as contribuições dos movimentos sociais para a EA e as lacunas do conhecimento sobre essa temática, justifica-se a realização deste trabalho. Nesse sentido, a pesquisa 
em questão tem como objetivo investigar que relações têm sido estabelecidas entre movimentos sociais e Educação Ambiental nas teses e dissertações (TD) em Educação Ambiental no país. Assim, a pesquisa foi realizada a partir das seguintes questões norteadoras: que compreensões sobre movimento social têm sido elaboradas pelas TD em EA? Que movimentos sociais são considerados nesses estudos? Que relações entre EA e movimentos sociais são estabelecidas nesses trabalhos?

Para o estudo e interpretação dos dados utilizamos, como instrumento analítico, a análise de conteúdo proposta por Bardin (2009, p. 11), que se constitui como:

Um conjunto de instrumentos metodológicos cada vez mais sutis em constante aperfeiçoamento que se aplicam a "discursos" (conteúdos e continentes) extremamente diversificados. O fator comum dessas técnicas múltiplas e multiplicadas - desde o cálculo de frequências que fornece dados cifrados até a extração de estruturas traduzíveis em modelos - é uma hermenêutica controlada baseada na dedução: a inferência. Enquanto esforço de interpretação, a análise de conteúdo oscila entre os dois polos, do rigor da objetividade e da fecundidade da subjetividade. Absorve e cauciona o investigador por esta atração pelo escondido, o latente, o nãoaparente, o potencial de inédito (do não-dito), retido por qualquer mensagem.

Segundo Bardin (2009, p. 121), as análises mediadas por esse instrumento ocorrem em três etapas: (1) "A pré-análise"; (2) "A exploração do material"; e, por fim, (3) "O tratamento dos resultados: a inferência e a interpretação". A primeira etapa tem por objetivo a escolha dos documentos que serão submetidos à análise, no caso, composto por teses e dissertações, bem como, se necessário, a formulação de hipóteses para a elaboração de indicadores para a interpretação final. Para as etapas da exploração e tratamento dos resultados, uma das possibilidades é o uso das "unidades de codificação ou unidades de registro que compõem a mensagem" (BARDIN, 2009, p. 121).

Nessa perspectiva, os próximos itens do presente trabalho descrevem os procedimentos metodológicos adotados para a realização desta pesquisa, bem como as análises do corpus documental.

\section{Procedimentos de pesquisa}

Este trabalho se caracteriza como uma pesquisa documental qualitativa, de caráter bibliográfico, do tipo estado da arte ou estado do conhecimento. De acordo com Ferreira (2002), as pesquisas desse tipo trazem em comum

[...] o desafio de mapear e de discutir uma certa produção acadêmica em diferentes campos do conhecimento, tentando responder que aspectos e que dimensões vem sendo destacados e privilegiados em diferentes épocas e lugares, em que forma e em que condições vem sendo produzidas dissertações de mestrado, teses de doutorado, publicações em periódicos 
e comunicações em anais de congressos e seminários (FERREIRA, 2002, p. 258, grifo nosso).

A partir de determinados estágios em que se encontram os campos de pesquisa, esses estudos permitem o reconhecimento dos seus limites e possibilidades na superação dos desafios identificados nos campos de conhecimento. Dessa forma, considerando a trajetória e a consolidação da EA enquanto campo de conhecimento e a intensificação das pesquisas na área, ao longo das últimas décadas surge a necessidade de realização de estudos sistemáticos sobre os trabalhos produzidos.

Essa tarefa, a princípio, possui o intuito de conhecer as características e tendências do campo de conhecimento por meio da produção acadêmica a ele vinculado, além de possibilitar uma divulgação mais ampla e adequada dessa mesma produção (MEGID NETO, 2009). Segundo o autor, as pesquisas do tipo estado da arte, para além dos aspectos quantitativos, podem avaliar a qualidade da produção científica, a coerência entre os objetivos da pesquisa e seus delineamentos metodológicos.

Nessa direção, o corpus documental analisado nesta pesquisa é composto por teses e dissertações do campo da Educação Ambiental, que abordam o tema movimentos sociais, constantes do Banco de Dados do Projeto E Arte disponíveis no período de 1981 até 2012. Os trabalhos publicados nos anos de 2010, 2013, 2014 e 2015 não disponíveis no banco de dados por ocasião da realização deste trabalho, foram buscados na Biblioteca Digital Brasileira de Teses e Dissertações (BDTD).

A constituição do corpus documental para análise compreendeu as seguintes etapas: definição dos termos de busca: leitura flutuante dos resumos encontrados, definição de critérios para seleção, busca e leitura dos trabalhos completos e, por fim, definição do corpus documental definitivo. Na continuidade, detalhamos essas etapas.

A partir do referencial teórico adotado nesta pesquisa, e após algumas buscas preliminares, optamos por adotar os seguintes termos de busca: movimentos sociais, movimento social, movimento ambientalista, movimento ecológico, MST, MAB e feminismo. Como resultados dessa busca foram identificados 148 trabalhos, sendo que 128 foram encontrados no Banco de Dados do Projeto EArte e 20 na Plataforma BDTD.

Inicialmente, após a leitura flutuante desses resumos, percebemos que, muitos deles, apenas faziam referência aos termos, sem, no entanto, apresentar indícios de discussão sobre a temática, ao longo do trabalho. Observamos a recorrência da citação aos movimentos sociais ou ao movimento ambientalista na contextualização histórica da EA, mas sem aprofundamento em questões que envolvem, de fato, os movimentos sociais e, sobretudo,sem estabelecer relações com a EA. Sendo assim, esses trabalhos não foram incluídos no corpus documental.

Houve recorrência de TD que, nos títulos, resumos e/ou palavras-chave, referiam-se aos termos de busca, mas tinham como foco de pesquisa as entidades que compõem o terceiro setor, como as Organizações Não Governamentais (ONG), e até mesmo as denominavam como movimento social ou movimento ambientalista.

\footnotetext{
${ }^{2}$ Os referidos bancos de dados podem ser acessados nos respectivos endereços eletrônicos: < http://earte.net. br $>$ e $<$ http://bdtd.ibict.br $>$
} 
Montaño (2002) explana que, embora na literatura não exista consenso sobre a conceituação terceiro setor, são tidos como integrantes dessa categoria as organizações não governamentais (ONG), as organizações sem fins lucrativos (OSFL), as organizações da sociedade civil (OSC), as instituições filantrópicas, as associações de moradores ou comunitárias, as associações profissionais ou categoriais, os clubes, as instituições culturais, as instituições religiosas, entre outros.

De acordo com a conceituação elaborada por Gohn (2006) sobre movimento social,tais organizações, que compõem o chamado terceiro setor, possuem características próprias que as distinguem dos movimentos sociais.

Como indicado anteriormente, não existe, no campo da sociologia dos movimentos sociais, uma única definição sobre o que é movimento social e consequentemente, dos grupos que os compõem. Nessa perspectiva, para autores como Martins (2016), outras formas de ações coletivas devem ser consideradas enquanto movimentos sociais, incluindo o chamado terceiro setor. $\mathrm{O}$ autor tem como fundamento a noção de que para a análise dos movimentos sociais interessa o fator de impacto de determinada ação coletiva na sociedade para que esta seja considerada um movimentos social e não sua estrutura organizacional, grau de institucionalização, fontes de recursos financeiros, entre outros aspectos relevantes para a conceituação elaborada por Gohn (2006). De acordo com o referencial teórico adotado (GOHN, 2006), e a fim de realizar um recorte na produção acadêmica (teses e dissertações), para a constituição desse corpus documental, os trabalhos que tinham como objetivo de estudo as organizações que compõem o terceiro setor não foram incluídos.

Além disso, trabalhos que tinham como lócus de pesquisa assentamentos do MST, contudo não discutiam os movimentos sociais ou o movimento em si, não foram incluídos na constituição do corpus documental.

Definidos esses critérios, foram excluídos 104 trabalhos, 34 passaram a constituir a categoria dúvida e dez foram incluídos no corpus documental. Na etapa seguinte, buscamos os textos completos das TD alocadas nas categorias dúvida e inclusão. As buscas foram realizadas nas bibliotecas digitais das universidades nas quais foram desenvolvidas as pesquisas. Em alguns casos, quando os trabalhos não estavam disponíveis, recorreu-se ao autor(a) e orientador(a) por meio de email e pela rede social facebook. Com esses procedimentos, apenas um trabalho não foi encontrado, totalizando 31 trabalhos que atendiam aos critérios apresentados anteriormente.

Após a leitura desses trabalhos completos, nos concentrando nos objetivos e questões de pesquisa, bem como no referencial teórico relativo a movimentos sociais que nortearam o desenvolvimento desta investigação, buscamos identificar, dentre esses 31 trabalhos, aqueles que traziam, de forma explícita, uma discussão sobre a relação entre EA e movimentos sociais. Sendo assim, foram selecionadas TD nas quais são apresentadas pelos autores relações diretas entre EA e movimentos sociais em seus objetivos e/ou questões de pesquisa. Após a definição desse critério, foram selecionadas nove TD, descritas no Quadro 1. 
Quadro 1 - Títulos e excertos dos trabalhos que apresentam relações explícitas entre movimentos sociais e educação ambiental nos objetivos e/ou nas questões de pesquisa

\begin{tabular}{|c|c|}
\hline Título & Objetivos e/ou questões de pesquisa \\
\hline $\begin{array}{l}\text { Tr1: A lógica destrutiva } \\
\text { do capital, crise ambiental, } \\
\text { mudanças climáticas: os } \\
\text { movimentos sociais e a } \\
\text { educação ambiental }\end{array}$ & $\begin{array}{l}\text { "Quais as contribuições que a educação ambiental e o método } \\
\text { materialismo histórico-dialético podem oferecer para compreensão } \\
\text { articulada dos movimentos sociais e ambientais?” (ZACARIAS, 2012, } \\
\text { p. 12). }\end{array}$ \\
\hline $\begin{array}{l}\text { Tr3: A questão agrária e o } \\
\text { meio ambiente: trabalho e } \\
\text { educação na luta pela terra } \\
\text { e pela sustentabilidade }\end{array}$ & $\begin{array}{l}\text { "Examinar os processos formativos elaborados pelos sujeitos do } \\
\text { campo, identificados nos documentos sobre educação produzidos pelo } \\
\text { MST, buscando interfaces teórico-metodológicas que contribuam na } \\
\text { construção de uma Educação Ambiental Transformadora ou Crítica, } \\
\text { definida conforme as necessidades de superação das condições de } \\
\text { alienação as quais os trabalhadores e trabalhadoras do campo estejam } \\
\text { submetidos." (VARGAS, 2007, p. 23). }\end{array}$ \\
\hline $\begin{array}{l}\text { Tr6: De coisa de pequeno } \\
\text { burguês para um debate } \\
\text { relevante: a trajetória } \\
\text { ambiental do movimento } \\
\text { dos trabalhadores rurais } \\
\text { sem terra (MST): } 1984- \\
2004\end{array}$ & $\begin{array}{l}\text { "Teve como objetivo principal identificar a Educação Ambiental que } \\
\text { vem sendo construída neste movimento social, considerando o período } \\
\text { de análise de } 1984 \text { a 2004.” (VIGNATTI, 2006, p. 7). }\end{array}$ \\
\hline $\begin{array}{l}\text { Tr8: Ecologias: sobre } \\
\text { processos educativos } \\
\text { livres e libertários em } \\
\text { movimentos sociais pós- } \\
\text { modernos }\end{array}$ & $\begin{array}{l}\text { "O objetivo geral deste projeto é, a partir do prisma da educação, } \\
\text { lançar alguma luz sobre a atual fase da luta pela emancipação humana } \\
\text { e construção de uma nova sociedade, identificando alguns pontos } \\
\text { de aproximação entre movimentos sociais de diferentes atuações e } \\
\text { interpretar algumas das principais potencialidades de alinhamento dos } \\
\text { movimentos sociais contemporâneos.Nesse contexto, buscaremos } \\
\text { destacar o papel da educação política e ambiental nos processos } \\
\text { abordados, bem como a apropriação de tais elementos pelos atores } \\
\text { envolvidos e a emergência de um novo paradigma contemporâneo, a } \\
\text { pós-modernidade libertária." (FRANQUES, 2014, p. 22). }\end{array}$ \\
\hline $\begin{array}{l}\text { Tr11: Educação ambiental } \\
\text { nos assentamentos do MST }\end{array}$ & $\begin{array}{l}\text { "Objetivo Geral: analisar as concepções e a prática dos/as assentados/ } \\
\text { as sobre meio ambiente e EA nos assentamentos rurais da reforma } \\
\text { agrária acompanhados pelo MST. [...] Objetivos Específicos: Conhecer } \\
\text { as propostas do movimento nos seus principais documentos, partindo } \\
\text { dos princípios e do documento "Construindo o programa Ambiental } \\
\text { do MST para Reforma Agrária" e a EA nas áreas de assentamentos } \\
\text { e intervir com o projeto teatro de bonecos na EA; fazer o resgate } \\
\text { histórico da EA em nível internacional, no Brasil e na Paraíba; refletir } \\
\text { sobre a EA e os elementos da cultura dos trabalhadores assentados } \\
\text { á luz dos conhecimentos freireanos; discutir sobre a concepção de } \\
\text { meio ambiente e os elementos da cultura, identificando práticas das } \\
\text { assentadas e dos assentados relacionando-as com a EA." (GALVÃO, } \\
\text { 2006, p. 18). }\end{array}$ \\
\hline
\end{tabular}


Quadro 1 - continuação

\begin{tabular}{|c|c|}
\hline Título & Objetivos e/ou questões de pesquisa \\
\hline $\begin{array}{l}\text { Tr16: Flores, cores e } \\
\text { saberes do movimento } \\
\text { ecológico de Mato } \\
\text { Grosso em frutificação na } \\
\text { educação ambiental }\end{array}$ & $\begin{array}{l}\text { “Temos como objetivo aprofundar a reflexão acerca das concepções } \\
\text { e conexões que fundamentam a educação ambiental; registrar e } \\
\text { interpretar os depoimentos e pensamentos dos pioneiros(as), desde o } \\
\text { início do movimento ecológico até os dias atuais. O objeto é interpretar } \\
\text { a percepção sobre o movimento ecológico por seus protagonistas e a } \\
\text { interface deste movimento com a educação ambiental em Mato Grosso, } \\
\text { tendo como contexto o adensamento dos movimentos sociais e } \\
\text { particularmente aqueles que atuam com a questão ambiental.” (FANK, } \\
2007, \text { p. 18). }\end{array}$ \\
\hline $\begin{array}{l}\text { Tr22: Movimento dos } \\
\text { Atingidos por Barragens } \\
\text { (MAB), a questão } \\
\text { ambiental e a participação } \\
\text { política }\end{array}$ & $\begin{array}{l}{[\ldots] \text { "pareceu-me pertinente propor como objeto de investigação }} \\
\text { das relações entre a questão ambiental e um movimento social } \\
\text { específico - o Movimento dos Atingidos por Barragens (MAB) [...] } \\
\text { Como se situa a educação ambiental, considerada como uma forma } \\
\text { de participação política, no cotidiano do MAB e na narrativa de seus } \\
\text { sujeitos, sobretudo de líderes e de moradores do reassentamento Novo } \\
\text { Alagamar?" (ARAÚJO, 2006, p. 18). }\end{array}$ \\
\hline $\begin{array}{l}\text { Tr26: Os movimentos } \\
\text { sociais como instrumento } \\
\text { dos processos de criação } \\
\text { e de implantação de } \\
\text { unidades de conservação } \\
\text { no Distrito Federal: um } \\
\text { estudo comparativo dos } \\
\text { Parques do Gama e Parque } \\
\text { Ecológico de Águas Claras }\end{array}$ & $\begin{array}{l}{[\ldots] \text { "o presente trabalho espera apresentar um estudo sobre os }} \\
\text { movimentos sociais do Distrito Federal que se articularam e deram } \\
\text { origem ao movimento ambientalista na região, priorizando os } \\
\text { movimentos relacionados à criação, implantação e gestão ambiental } \\
\text { das unidades de conservação das cidades do Gama e de Águas } \\
\text { Claras, associando-os aos processos de educação ambiental, como } \\
\text { instrumentos de movimentos sociais ambientalistas." (BARBOSA, } \\
2006 \text {, p. 29). }\end{array}$ \\
\hline $\begin{array}{l}\text { Tr31: desafios da } \\
\text { ducação ambiental na } \\
\text { articulação entre escola e } \\
\text { assentamentos da reforma } \\
\text { agrária }\end{array}$ & $\begin{array}{l}\text { "Sendo múltiplos os espaços em que a EA vem sendo apreciada e } \\
\text { desenvolvida, gostaria de dizer que me parece de grande oportunidade } \\
\text { uma pesquisa que busque estudar de que forma em um movimento } \\
\text { social, como o Movimento dos Trabalhadores Rurais Sem Terra } \\
\text { (MST), que vive a terra, na terra e para a terra, se pensa e pratica a EA. } \\
\text { Busquei, já no título desta dissertação, demonstrar a pertinência desta } \\
\text { interação entre a escola e assentamentos da Reforma Agrária mediante } \\
\text { a interface da EA." (GUIMARÃES, 2004, p. 1). }\end{array}$ \\
\hline
\end{tabular}

Fonte: elaborado pelas autoras a partir dos dados da pesquisa.

Tendo em vista esse recorte do corpus documental e o objetivo desta pesquisa, no próximo item enfocamos a análise desses nove trabalhos no que se referem aos movimentos sociais estudados, às compreensões sobre movimentos sociais presentes nessas pesquisas e às possíveis relações estabelecidas entre EA e MS pelos pesquisadores.

\section{Os movimentos sociais nas teses e dissertações de educação ambiental}

Neste item apresentamos e discutimos alguns excertos dos trabalhos que permitem explorar os aspectos evidenciados nas nossas questões de pesquisa, selecionados a partir do 
referencial teórico adotado. Para facilitar a leitura e diferenciar os excertos dos trabalhos analisados, optamos por utilizar um recuo menor que o utilizado para as demais citações diretas. Adotou-se como identificação dos trabalhos a sigla Tr e um número de referência.

Conhecer os movimentos sociais que vêm sendo objetos de estudo no campo da EA constitui um primeiro passo para uma possível construção de diálogos entre esse campo de pesquisa e esses movimentos. Dentre os nove trabalhos selecionados para compor esta etapa de análise, os movimentos sociais campesinos tiveram destaque enquanto objeto científico de estudo, sendo que a maioria dos trabalhos enfoca as relações entre EA e o Movimento dos Trabalhadores Rurais Sem Terra (MST). Também foi expressiva a presença de trabalhos que se propõem a analisar a EA no contexto do movimento ambientalista/ecológico.

Ainda que, de acordo com Acserald (2010), os movimentos sociais campesinos, nesse caso representados pelo MST e o MAB, não se autodenominem ambientalistas, os mesmos estão inseridos em uma das correntes do ambientalismo elaboradas por Alier (2015), a do ecologismo dos pobres, que tem como um dos seus eixos de discussão a questão da justiça ambiental. Essa expressividade pode ser compreendida, uma vez que as raízes da educação ambiental encontram-se no movimento ambientalista e que, na sua vertente crítica, a justiça ambiental é um tema que vem sobressaindo, principalmente a partir das últimas décadas.

Atualmente, é possível traçarmos relações entre questão agrária e questão ambiental e, ainda, pela perspectiva da EA crítica, entre educação ambiental e movimentos sociais do campo. No entanto, essa possibilidade pode ser considerada recente, e nos remete auma situação recorrente nos trabalhos analisados: a incorporação da temática ambiental por esses movimentos sociais.

No geral, as pesquisas que compõem o corpus documental desta investigação apontam que, ao longo dos anos, os movimentos sociais campesinos, representados nas pesquisas pelo MST e pelo MAB, foram incorporando a dimensão ambiental na medida em que a própria questão agrária foi se tornando uma questão ambiental. Podemos inferir, então, que houve um processo de ambientalização das lutas camponesas. O percurso inverso também pode ser observado quando atentamos para a corrente do ecologismo dos pobres do movimento ambientalista, que considera a justiça ambiental, os conflitos de luta pela terra e os movimentos sociais como uma questão ambiental, ou seja, houve um processo de politização das lutas ambientais.

Embora sejam reconhecidas, as relações entre a defesa da naturez̧a e alguns movimentos como o movimento de seringueiros da Amazônia, dos camponeses, dos indígenas e atingidos por barragens, de acordo com o Tr 22, fundamentado em Scherer-Warren (1993), passam, muitas vezes despercebidas pelos pesquisadores. A situação é ainda mais recorrente quando pensamos nas relações entre a educação ambiental e os movimentos sociais do campo. $\mathrm{O} \mathrm{Tr}$ 31, ao realizar um trabalho em um movimento social específico, no caso, o MST, aponta essa questão que delimitou o seu problema de pesquisa:

Sabe-se que existem inúmeros trabalhos realizados sobre a questão educacional, aquestão agrária e a questão ambiental. Também são conhecidas pesquisas que envolvem a área educacional com a agrária, bem como outras que envolvem a área educacional com aambiental, mas, até o momento, se desconhecem pesquisas que abordem a articulação entre escola e assentamentos da Reforma Agrária pelo viés da EA. É justamente aí que seen- 
contra a problemática da presente pesquisa: mediante o desenvolvimento de um estudoprofundo, sobre a questão educacional e agrária, a partir da visão ambiental, buscar aarticulação entre a escola e o assentamento. ( $\mathrm{Tr}$ 31, GUIMARÃES, 2004, p. 2).

Ainda sobre as questões agrárias e ambientais, foi recorrente nas pesquisas analisadas a temática agroecologia e a modalidade da Educação do Campo. Embora seus caminhos ainda estejam sendo trilhados, é perceptível que a agroecologia vem ganhando espaço, principalmente nos movimentos sociais do campo. Muitas vezes, tem sido considerada um elo entre o agrário e o ambiental, uma vez que suas preocupações incluem a preservação da biodiversidade, a luta contra os agrotóxicos, contra o modo de produção capitalista e, consequentemente, do agronegócio e pela construção de outra relação com a terra, e, também, entre ser humano e natureza. Dentre os trabalhos que abordam a agroecologia, foram expressivos aqueles relativos à Educação do Campo. Concordamos com os apontamentos de algumas pesquisas, no que se refere às possibilidades de diálogos entre essa modalidade de ensino e a EA em uma perspectiva crítica e transformadora, tendo em vista seus princípios e propostas pedagógicas.

Ressaltamos que, no campo de pesquisa da EA, principalmente para aqueles que se orientam pelas perspectivas críticas, discute-se, na produção científica e nos encontros nacionais de pesquisas, a importância da inclusão dos movimentos sociais de forma mais consistente nos debates da EA. No entanto, cabem alguns questionamentos: o que esses pesquisadores estão entendendo por movimento social? Quais organizações estão sendo consideradas como movimentos sociais? Sob quais teorias interpretativas estão sendo analisados? Ou ainda, as pesquisas apresentam dados que permitam responder a essas questões? Com o intuito de buscar elementos que auxiliem na elaboração de possíveis caminhos para responder tais questões, procuramos, nos trabalhos analisados, as compreensões sobre os movimentos sociais que, de forma explícita ou implícita, são construídas pelos autores.

No geral, podemos considerar que houve a preocupação em elucidar as compreensões sobre movimento social por parte dos autores das pesquisas que constituem o corpus documental analisado. Para o Tr 1, movimento social pode ser caracterizado como

[...] uma organização, com relativo grau de formalidade e de estabilidade, que não se reduz a uma dada atividade de mobilização [...] e que tem como determinações: ser "conformado pelos próprios sujeitos portadores de certa identidade/necessidade/reivindicação/pertencimento de classe que se mobilizam por respostas ou para enfrentar tais questões"'...].Estas características diferem os movimentos sociais de uma ONG. (Tr 1, ZACARIAS, 2012, p. 102).

$\mathrm{Na}$ maioria das pesquisas, a discussão entre novos ou velhos movimentos sociais, cara ao campo da sociologia dos movimentos sociais, foi explicitada. Em relação à inserção desses movimentos nessas categorias, houve divergências entre os autores. Alguns consideram como novos aqueles que lutam apenas por pautas pós-estruturalistas, restritas ao campo da identidade e da cultura. Para outros, esta novidade não rompe com as transformações estruturais, sendo assim, a categoria de classe não é excluída. Em um caso, as abordagens marxistas, clássicas ou novas, 
foram rejeitadas e substituídas pelos ideais anarquistas, considerando o anarquismo enquanto um movimento pós-moderno.

Consideramos que a ambiguidade na tentativa de enquadramento de um movimento, no caso o MST, em uma ou outra categoria, pode ser explicada pelo paradigma latino-americano de análise dos movimentos sociais (GOHN, 2006), ou ainda, pela ausência de uma elaboração teórica mais sólida desse paradigma. O contexto latino-americano, no qual se desenvolveram os movimentos sociais, apresenta características específicas em relação aos movimentos sociais de ocorrência na Europa e nos países norte-americanos, principalmente nos Estados Unidos.

$\mathrm{Na}$ tentativa de elencar elementos essenciais a serem considerados para a formulação de um paradigma de análise próprio da América Latina, Gohn (2006) afirma que, no contexto latino-americano, houve a presença dos novos movimentos sociais (de mulheres, de negros, ecológicos etc.), porém, não de forma tão expressiva e de amplitude nacional como os casos europeus e norte-americanos. Além disso, a sociedade civil latino-americana foi marcada por regimes autoritários, tradições clientelistas e pela fragilidade do sistema judiciário, no qual a tradição de cultura política democrática praticamente inexiste, e as questões referentes ao modo de vida (GONÇALVES, 1990), como o machismo e os preconceitos, ou seja, não podem ser consideradas novas nesse contexto.

Segundo Gohn (2006), enquanto nos EUA e na Europa o foco das lutas por direitos humanos residiam na luta por direitos sociais e culturais, na América Latina as demandas materiais ainda se faziam presentes, sendo que a luta tinha como pauta os direitos econômicos indispensáveis para a sobrevivência dos seres humanos. A esse respeito, Gohn (2006) afirma concordar com Alan Touraine, autor europeu que se dedicou a estudar os movimentos sociais na América Latina, que "reconhece que as demandas econômicas seguem relevantes na América Latina; no entanto, para englobar seus movimentos dentre os 'novos', argumenta que haveria aqui uma combinação sui generis de demandas materiais e pós-materiais”. (TOURAINE, 1989 apud ALONSO, 2009, p. 68).

Além disso, os trabalhos consideram o movimento ambientalista/ecológico enquanto um movimento social, que pode ser inserido na categoria dos novos movimentos sociais, cada qual com sua justificativa para tal e, no entanto, consideram que as ONG identificadas em seus trabalhos podem ser denominadas como movimento social. Ao tomar como objeto de análise o movimento ambientalista, há que se considerar todas essas organizações, tendo em vista o caráter difuso desse movimento (ACSELRAD, 2010), ou seja, a diversidade de organizações que o compõem e, principalmente, as suas distinções em relação a outros tipos de organizações sociais.

Sobre as relações entre EA e movimentos sociais, estabelecidas pelos autores das pesquisas analisadas, apenas em um trabalho não foi possível identificá-las. Para o $\operatorname{Tr} 1$, a EA em sua perspectiva crítica, juntamente com o marxismo, pode trazer contribuições aos movimentos sociais comprometidos com a emancipação social, uma vez que fornece subsídios para uma compreensão dos problemas ambientais e sociais existentes na sociedade de forma articulada.Trilhando um caminho inverso, porém não antagônico, o $\operatorname{Tr} 3$ aborda a contribuição dosmovimentos sociais para a EA crítica:

Não se trata, portanto, de compreender como a Educação Ambiental pode contribuir para esta transformação, mas como esta transformação posta já em movimento pode contribuir para a constituição de uma Educação Ambiental que se mostre efetivamente Transformadora, que assuma a ga- 
rantia e conquista dos direitos e a capacidade de intervenção popular nas decisões de interesse coletivo como condicionantes políticos de mudança nas relações sociedade-natureza. ( $\operatorname{Tr} 3$, VARGAS, 2007, p. 29).

Para alguns trabalhos, a EA é intrínseca aos movimentos analisados e é contemplada enquanto um processo educativo, como afirma o $\operatorname{Tr} 11$ :

A luta e a conquista da terra pelo MST, em si, já pode ser considerada um primeiro passo para que a EA esteja sendo vivida. Porque a luta pela terra, para que nela se produza com respeito ao ambiente é algo que vem sendo deixado explicito nos documentos do movimento e experienciado em algumas regiões. A EA é vivida na busca por um pedaço de chão, como uma luta política, educativa e ambiental, no sentido de ser implantada nos assentamentos, dentro do sistema de cooperação coletiva e individual. ( $\mathrm{Tr}$ 11, GALVÃO, 2006, p. 139).

De forma semelhante, o $\operatorname{Tr} 16$, que analisa o movimento ecológico do Mato Grosso, entende que, mesmo que no início da constituição desse movimento a EA não seja pautada do ponto de vista formal, essa se faz presente de forma intrínseca, tendo em vista os princípios, discursos e ações do movimento. No entanto, o trabalho aponta que a EA propriamente dita vai se consolidando a partir de processos educativos intencionais em espaços não formais:

No início do movimento, década de 80, o termo educação ambiental não era entendido e tratado como tal, mas as discussões e ações eram direcionadas a este tema. No decorrer do tempo, este vocábulo começa aparecer com mais freqüência e se transformar numa discussão e preocupação global. Segundo Fonteles [entrevistado 01], “não bá nada que possa afastar o movimento ecológico da educação ambiental por que são uma só entidade" [depoimento pessoal]. As pessoas entendiam que uma das soluções eram trabalhos onde a educação estava imbricada. Em 87, houve um curso de educação ambiental na Universidade de São Paulo (USP) e ecologistas mato-grossenses participaram. Quando retornaram, repassaram o conteúdo através de outro curso, como forma de multiplicar ou replicar aos interessados. Era o tempo de construção deste processo. A maneira que dialogavam e faziam as manifestações e ações, era através da educação não escolarizada. Estas vertentes, ambiental e educativa se mantêm até hoje. ( $\operatorname{Tr} 16$, FANK, 2007, p. 142).

Para o $\operatorname{Tr}$ 6, a EA não existe intrinsecamente nos princípios e práticas dos movimentos, no caso o MST, mas sim, é um processo em construção, seja devido aos fatores internos, seja aos fatores externos, e que tem como fundamento as propostas de educação popular e apedagogia da libertação, idealizadas por Paulo Freire, incorporando, ainda,ospressupostos políticos, históricos e filosóficos da Educação do Campo. Para o Tr 6, embora do ponto de vista da educação formal a EA não seja uma preocupação educativa específica do MST, pode-se considerar que “[...] todas as ações de aproximação e de abordagem da temática ambiental realizadas pelo MST, a partir de 
meados da década de 90, como um processo de educação ambiental, representado pela tomada de consciência via os processos educativos" (Tr 6, VIGNATTI, 2005, p. 105).

Assim como o Tr 1, o Tr 31 aborda a contribuição da EA para o MST. De acordo com o trabalho, a EA pode contribuir para o desenvolvimento de novas formas de relação entre os integrantes do MST e anatureza, visto que discursos e práticas ainda têm como base a visão antropocêntrica da natureza:

Não se pode dizer que essa preocupação não exista no Movimento, mas, ainda graça, entre boa parte dos integrantes do Movimento, a cultura arraigada que domina em nossa sociedade, de uma não identificação do ser humano como pertencente, junto com o resto dos seres animados e inanimados, a uma natureza única. É aí que entra a importância da Educação Ambiental na construção do "novo" a que o MST se propõe. (Tr 1, ZACARIAS, 2004, p. 91).

Entendemos que a educação ambiental está sendo construída, nesses movimentos, em um processo lento e a partir de fatores internos e externos aos próprios movimentos, e que, nas últimas décadas, algumas ações com intencionalidades educativas, sejam elas formais ou não formais, podem ser consideradas como atividades de educação ambiental ou, pelo menos, como um início da construção da EA nesses movimentos, como aponta o $\operatorname{Tr} 6$. Afirmar que a EA existe em determinado movimento somente a partir da vivência dos sujeitos pode comprometer a própria prática pedagógica da EA, uma vez que se desconsideram as suas especificidades e intencionalidades.

\section{Considerações finais}

Identificamos, nesta pesquisa, além do movimento ambientalista e/ou ecológico, no qual a temática ambiental sempre foi inerente às suas lutas, os movimentos sociais campesinos, representados pelo MST e pelo MAB. Em apenas um trabalho observamos alguma discussão sobre o movimento feminista. Em relação ao MST e ao MAB, identificamos nas pesquisas que esses movimentos sociais foram incorporando a dimensão ambiental na medida em que a própria questão agrária foi se tornando uma questão ambiental.

Podemos considerar que houve um processo de ambientalização das lutas camponesas e a politização das lutas ambientais. Nesse sentido, foi recorrente a discussão sobre a agroecologia e a Educação do Campo como possibilidades de articulação entre questão agrária e ambiental, bem como suas possibilidades de diálogo com a EA na perspectiva crítica. Contudo, consideramos, ainda, que a relação entre os processos educativos do campo e a agroecologia constituem lacunas no campo da EA, sugerindo que esses temas devem ser incluídos nas agendas dos pesquisadores.

Das pesquisas que indicaram analisar os movimentos sociais e a sua relação com a EA, não foi possível identificar tais relações em apenas um trabalho. No geral, esses trabalhos atingiram os objetivos propostos ao apresentarem as relações entre EA e os movimentos estudados. Para alguns, a EA é intrínseca aos movimentos e, para outros, ela vem sendo construída, seja devido aos fatores externos seja aos fatores internos dos movimentos em questão. 
Observamos que, na maioria dos trabalhos foi adotado o referencial da EA crítica ou transformadora. Além disso, foram recorrentes as contribuições da EA para os movimentossociais e, também, dos movimentos sociais para a construção da EA em sua perspectiva crítica. Sendo assim, consideramos que a relação entre EA e movimentos sociais ocorre de maneira mútua, bidirecional e interligada, na qual ambos se transformam e são beneficiados. Cabe ressaltar, no entanto, que existem desafios a serem superados para a construção dos diálogos como, por exemplo, a existência de algumas pesquisas que discutem práticas de cunho exclusivamente intervencionista da EA em assentamentos acompanhados por movimentos sociais, configurando certo pragmatismo para a EA, além de demonstrarem certo otimismo pedagógico em relação ao papel da EA.

No geral, as pesquisas em EA que tematizam os movimentos sociais evidenciam a dimensão política e social da temática ambiental e da educação ambiental, com referenciais demarcados e que consideram a superação do modo de produção capitalista para o enfrentamento da crise socioambiental. Entendemos que, partindo da noção de justiça ambiental, os conflitos socioambientais e os movimentos sociais constituem elementos fundamentais para a consolidação de uma educação ambiental crítica.

Por fim, esperamos que com esses conhecimentos construídos seja possível o estreitamento das relações entre o campo da pesquisa em educação ambiental e dos movimentos sociais que,embora com especificidades próprias e desafios a serem superados, caminham juntos no sentido de opor resistência às injustiças socioambientais e buscam a transformação da realidade socioeconômica e política atual.

\section{Agradecimentos}

As autoras agradecem o financiamento da Coordenação de Aperfeiçoamento de Pessoal de Nível Superior (CAPES).

\section{Referências}

ACSELRAD, H. Ambientalização das lutas sociais: o caso do movimento de justiça ambiental. Estudos Avançados, São Paulo, v. 24, n. 68, p. 103-120, 2010. DOI: https://doi. org/10.1590/S0103-40142010000100010.

ALIER, J. M. O ecologismo dos pobres. São Paulo: Contexto, 2015.

ALONSO, A. As teorias dos movimentos sociais: um balanço do debate. Lua Nova, São Paulo, n. 76, p. 49-86, 2009. DOI: https://doi.org/10.1590/S0102-64452009000100003.

ARAÚJO, C. V. O Movimento dos atingidos por barragens (MAB), a questão ambiental e a participação política. 2006. Dissertação (Mestrado em Desenvolvimento e Meio Ambiente) - Universidade Federal do Ceará, Fortaleza, 2006. 
BARBOSA, F. M. Os movimentos sociais como instrumento dos processos de criação e de implantação de unidades de conservação no Distrito Federal: um estudo comparativo dos parques do Gama e parque ecológico de Águas Claras. 2006. Dissertação (Mestrado em Planejamento e Gestão Ambiental) - Universidade Católica de Brasília, Brasília, 2006.

BARDIN, L. Análise de conteúdo. Lisboa: Edições 70, 2009.

CARVALHO, L. M. A temática ambiental e a escola de $\mathbf{1}^{\mathbf{o}}$ grau. 1989. Tese (Doutorado em Educação) - Universidade de São Paulo, São Paulo, 1989.

CARVALHO, L. M. Temática ambiental e o processo educativo: dimensões e abordagens. In: CINQUETTI, H. S.; LOGAREZZI, A. (org.). Consumo e resíduos: fundamentos para o trabalho educativo. São Carlos: EdUFSCar, 2006. p. 19-41.

FANK, J. T. Flores, cores e saberes do movimento ecológico de Mato Grosso em frutificação na educação ambiental. 2007. Dissertação (Mestrado em Educação, cultura e sociedade) - Universidade Federal de Mato Grosso, Cuiabá, 2007.

FERREIRA, N. S. A. As pesquisas denominadas "estado da arte". Educação \&

Sociedade, Campinas, v. 23, n. 79, p. 257-272, 2002. DOI: https://doi.org/10.1590/S010173302002000300013.

FOLADORI, G. Limites do desenvolvimento sustentável. Campinas: Ed. Unicamp, 2001.

FRANQUES, B. M. Ecologias: sobre processos educativos livres e libertários em movimentos sociais pós-modernos. 2014. Dissertação (Mestrado em Educação) Universidade Federal de São Carlos, Sorocaba, 2014.

GALVÃO, M. N. C. Educação ambiental nos assentamentos rurais do MST. 2006. Tese (Doutorado em Educação) - Universidade Federal da Paraíba, João Pessoa, 2006.

GOHN, M. G. Teoria dos movimentos sociais: paradigmas clássicos e contemporâneos. São Paulo: Loyola, 2006.

GONÇALVES, C. W. P. Os (des)caminhos do meio ambiente. São Paulo: Contexto, 1990.

GUIMARÃES, R. S. Desafios da educação ambiental na articulação entre escola e assentamentos da reforma agrária. 2004. Dissertação (Mestrado em Educação Ambiental) -Universidade Federal do Rio Grande, Rio Grande, 2004.

KAWASAKI, C. S.; KATO, D. S.; VALDANHA NETO, D.; SOUZA, J. C. B.; OLIVEIRA, L. B.; MATOS, M. S. A pesquisa em educação ambiental nos ENPECS: contextos educacionais e focos temáticos. In: ENCONTRO NACIONAL DE PESQUISADORES EM EDUCAÇÃO EM CIÊNCIAS, 7., 2009, Florianópolis. Anais [...]. Florianópolis: UFSC, 2009.

LAYRARGUES, P. P.; LIMA, G. F. C. As macrotendências político-pedagógicas da educação ambiental brasileira. Ambiente \& Sociedade, São Paulo, v. 17, n. 1, p. 23-40, 2014. Disponível em: http://www.scielo.br/scielo.php?script=sci_arttext\&pid=S1414-753X201400 0100003\&lng=en\&nrm=iso\&tlng=pt. Acesso em: 11 fev. 2019. 
LEFF, E. Epistemologia ambiental. São Paulo: Cortez, 2001.

LOUREIRO, C. F. B. Educação ambiental e movimentos sociais: reflexões e questões levantadas no GDP. Pesquisa em Educação Ambiental, Rio Claro, v. 3, n. 1, p. 187-201, 2008. DOI: https://doi.org/10.18675/2177-580X.vol3.n1.p187-201.

MARTINS, M. F. Apontamentos sobre o conservadorismo contemporâneo: os movimentos sociais e os eventos de multidão à luz de Gramsci. In: VARES, S. F.; POLLI, J. R. Democracia em tempos de conservadorismo. Jundiaí: Editora In House, 2016. p. $140-173$.

MEGID NETO, J. Educação ambiental como campo de conhecimento: a contribuição das pesquisas acadêmicas para sua consolidação no Brasil. Pesquisa em Educação Ambiental, Rio Claro, v. 4, n. 2, p. 95-110, 2009. DOI: https://doi.org/10.18675/2177-580X.vol4. n2.p95-110.

MONTAÑO, C. Terceiro setor e questão social: crítica ao padrão emergente de intervenção social. São Paulo: Cortez, 2002.

PASCUAL RODRÍGUEZ, M.; HERRERO LÓPEZ, Y. Ecofeminismo: una propuesta para repensar el presente y construir el futuro. Boletín ECOS: CIP-Ecosocial, Madrid, n. 10, p. 1-9, 2010. Disponível em: http://www.fuhem.es/ecosocial/boletin-ecos/numero.aspx?n=10. Acesso em: 11 fev. 2019.

SCHERER-WARREN, I. Redes de movimentos sociais. São Paulo: Loyola, 1993.

VARGAS, L. A. A. A questão agrária e o meio ambiente: trabalho e educação na luta pela terra e pela sustentabilidade. 2007. Dissertação (Mestrado em Educação) - Universidade Federal do Rio de Janeiro, Rio de Janeiro, 2007.

VASCONCELLOS, H. S. R.; SPAZZIANI, M. L.; GUERRA, A. F. S.; FIGUEIREDO, J. B. A. Espaços educativos impulsionadores da educação ambiental. Cadernos Cedes, Campinas, v. 29, n. 77, p. 29-47, 2009. DOI: https://doi.org/10.1590/S0101-32622009000100003.

VIGNATTI, M. A. P. De coisa de pequeno-burguês para um debate relevante: a história ambiental do movimento dos trabalhadores rurais sem terra. 2006. Dissertação (Mestrado em Educação) - Universidade Católica de Brasília, Brasília, 2006.

ZACARIAS, R. A lógica destrutiva do capital, crise ambiental, mudanças climáticas: os movimentos sociais e a educação ambiental. 2012. Tese (Doutorado em Serviço Social) Universidade Federal do Rio de Raneiro, Rio de Janeiro, 2012.

Artigo recebido em 26/10/2017. Aceito em 25/08/2018.

Contato: UNESP, Instituto de Biociências, Avenida 24 A, 1515 Rio Claro, SP, 13506-899, Brasil. 
